\title{
Tecnologias Digitais de Informação e Comunicação (TDIC) na alfabetização de crianças
}

\section{Digital information and communication technologies (DICT) in children's literacy}

\author{
Marineide Gomes Alves ${ }^{1}$ \\ Maria Paulina Assis ${ }^{2}$
}

Resumo: Este trabalho trata de uma pesquisa de mestrado em andamento de natureza qualitativa, faz parte do Programa de Pós-Graduação em Educação-PPGEDUC da Universidade Federal de Catalão-GO. Consiste na análise de produções científicas sobre as Tecnologias Digitais de Informação e Comunicação-TDIC e suas vertentes acerca do processo da alfabetização nos anos iniciais do ensino fundamental. Nesta etapa da pesquisa foram selecionados oito trabalhos que compoem a análise deste artigo, utilizando-se a Revisão Sistemática da Literatura. Os resultados mostraram avanços ou direcionamentos de usos das TDIC aplicadas à alfabetização e limitações que sugerem políticas públicas que atendam as demandas atuais. Conclui-se que este campo de pesquisa apresenta potencial para contribuir para a formação e a prática docente.

Palavras-chave: TDIC. Alfabetização. Revisão Sistemática da Literatura.

Abstract: This work is an ongoing master's research of a qualitative nature, it is part of the Graduate Program in Education-PPGEDUC at the Federal University of Catalão-GO. It consists of the analysis of scientific productions on Digital Technologies of Information and Communication-TDIC and its aspects about the literacy process in the early years of elementary school. At this stage of the research, eight works were selected that make up the analysis of this article, using a systematic literature review. The results showed advances or directions of use of TDIC applied to literacy and limitations that public policies that meet current demands. It is concluded that this field of research has the potential to contribute to training and teaching practice.

Keywords: TDIC. Literacy. Systematic Literature Review.

\footnotetext{
${ }^{1}$ Mestrado em Educação, Universidade Federal de Catalão-GO, marineidegomes@ hotmail.com.br

${ }^{2}$ Mestrado em Educação, Universidade Federal de Catalão-GO, paulina@ ufcat.edu.br
}

Recebido em 23/01/2022

Aprovado em 10/02/2022

Sistema de Avaliação: Double Blind Review

OPEN

ACCESS 


\section{Introdução}

O objetivo deste texto é trazer um recorte de uma pesquisa de mestrado em andamento, de cunho bibliográfico, do Programa de Pós-Graduação em EducaçãoPPGEDUC, da Universidade Federal de Catalão-GO. Refere-se a uma Revisão Sistemática da Literatura, com a utilização da base de dados do Google Acadêmico, que tem como objetivo analisar artigos científicos nacionais, publicados em periódicos revisados por pares, que abordam o uso das tecnologias digitais de informação e comunicação-TDIC no contexto da alfabetização, nos anos iniciais do ensino fundamental.

O texto apresenta reflexões sobre a temática do uso das TDIC na alfabetização nos anos iniciais do ensino fundamental, buscando uma compreensão de como essas tecnologias se relacionam com o aprendizado de crianças nos anos iniciais do ensino fundamental.

Refletindo acerca dos diferentes impactos no campo educacional, precisamente nos anos iniciais da alfabetização, quanto ao uso das tecnologias digitais para o atendimento escolar, o problema da pesquisa de mestrado traz a seguinte questão: Quais os desafios e potencialidades nos usos das tecnologias digitais de informação e comunicação-TDIC, no processo de alfabetização nos anos iniciais do ensino fundamental evidenciados em artigos científicos nacionais?

Para avaliação inicial dos estudos foi realizado um teste piloto com cinco artigos selecionados dentro de um padrão específico da Revisão Sistemática da Literatura, para termos uma referência de continuidade ou não dos estudos.

A partir desses resultados preliminares optou-se por dar seguimento à pesquisa dada a pertinência dessa temática, enfatizando o uso das TDIC na perspectiva pedagógica e seus possíveis progressos ou não, ao serem utilizadas na alfabetização, assim como promover uma reflexão sobre seus usos na prática educacional de educadores/as.

Para a reflexão teórica deste texto, trouxemos Ferreiro e Teberosky (1999), Faria (2016), Martin-Barbero (2014), Silva (2020), Oliveira et al. (2020), Fantin (2018), Junior; Menez e Wunsch (2018), Kensky (2003), dentre outros, com o intuito de refletir como as tecnologias e a alfabetização são evidenciadas no processo de construção do conhecimento.

Este artigo de natureza qualitativa refere-se a uma Revisão Sistemática da Literatura realizada com oito artigos, formatado da seguinte forma: introdução contendo o resumo do andamento da pesquisa de mestrado, algumas reflexões sobre as TDIC no processo de 
alfabetização, metodologia, análise dos dados e discussão e as considerações finais.

\section{As TDIC no processo de alfabetização: algumas reflexões}

O tema do uso das TDIC na educação, nos remete ao pensamento das mudanças que podem ocorrer decorrente delas. O modo de aprender e ensinar vem se transformando à medida que avançamos no nosso tempo histórico, por um movimento mundial causado por uma epidemia da COVID-19, que obrigou os espaços sociais a se modificarem para continuar oferecendo seus serviços de forma mais segura afim de se resguardar a vida humana.

Nesse sentido, ainda que já estivéssemos em um processo histórico de mudanças, como cita Martin-Barbero (2014, p. 66):

A revolução tecnológica que vivemos não afeta apenas individualmente a cada um dos meios, mas produz transformações transversais que se evidenciam na emergência de um ecossistema educativo conformado não só por novas máquinas ou meios, mas por novas linguagens, escritas e saberes, pela hegemonia da experiência audiovisual sore a tipográfica e a reintegração da imagem ao campo da produção de conhecimentos.

A situação atual de emergência acelerou alterações na escolha dos recursos utilizados para as práticas de ensinar e aprender da atualidade e com isso, nos instigou a questionar como se dá esse processo, quais resultados foram verificados a respeito das tecnologias digitais quando aplicadas à alfabetização de crianças nos anos inicias do ensino fundamental.

Sobre os processos de aquisição da leitura e escrita Ferreiro e Teberosky (1999, p. 29) pontuam:

O sujeito que conhecemos através da teoria de Piaget é aquele que procura ativamente compreender o mundo que o rodeia e trata de resolver as interrogações que este mundo provoca. Não é um sujeito o qual espera que alguém que possui um conhecimento o transmita a ele por um ato de benevolência. É um sujeito que aprende basicamente através de suas próprias ações sobre os objetos do mundo e que constrói suas próprias categorias de pensamentos ao mesmo tempo que organiza seu mundo.

Dito isto, entendemos que ler e escrever vai além dos processos de decodificação e codificação dos sons dos fonemas em materiais escritos (BRASIL, 2018, p. 89-90), porque requer ação e compreensão na organização de pensamentos próprios de cada sujeito. Rojo (2010) ao discutir sobre os níveis de habilidades de leitura do alunado no Brasil, aponta: 


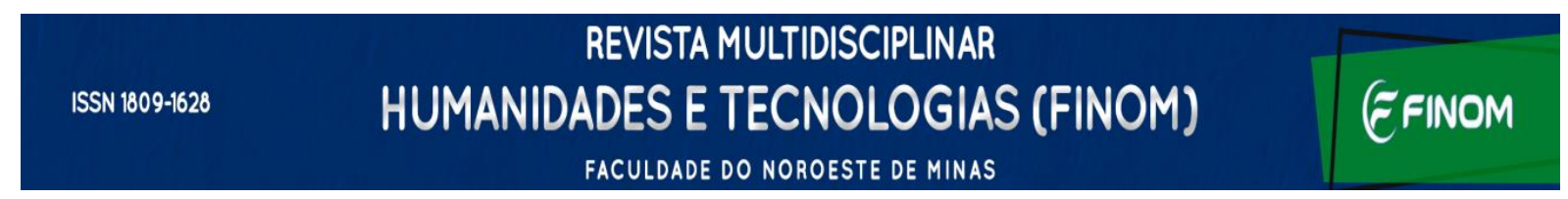

jeito nisso, mas, sim, eventos escolares de letramento que provoquem a inserção do alunado em práticas letradas contemporâneas e, com isso, desenvolovam as competências/capacidades de leitura e escrita requeridas na atualidade. (ROJO, 2010, p. 22-23).

Pensando na complexidade que envolve as questões relacionadas a alfabetização na atualidade, o nosso objeto de pesquisa se situa em trabalhos acadêmicos, no formato de artigos que evidenciam o uso das TDIC na alfabetização nos anos iniciais do ensino fundamental.

A pesquisa tem como objetivo geral analisar artigos científicos nacionais, publicados em periódicos revisados por pares, que abordam o uso das TDIC no contexto da alfabetização, nos anos iniciais do ensino fundamental.

Segundo Silva (2020, p. 3) "[...] a utilização de recursos tecnológicos permite às crianças diversas formas de aprendizagem, que os deixa estimulados para aprender. Com isso as aulas se tornam mais produtivas e as crianças mais envolvidas." Concordamos com a autora, pois as crianças estão imersas em meios digitais em seu cotidiano e trazer parte desse codidiano para o contexto escolar signfica somar à aprendizagem pois estará permeado de significados para os escolares.

Oliveira et al. (2020), trazem a questão dos professores e o uso das TDIC em tempos de pandemia, como resultado dos estudos relatam as limitações de formação docente, trazem a falta de infraestrutura e recursos tecnológicos tanto nas escolas como nos domicílios dos discentes em um município do Ceará, bem como expõem o uso de ferramentas digitais utlizadas pelos educadores para a realização das atividades didáticas.

Fantin (2018) sobre tecnologias digitais, apresenta a seguinte observação:

[...] observamos que os dispositivos móveis podem representar elementos de continuidade entre experiências cotidianas e âmbitos escolares em seu sentido afirmativo. [...] visto que os dispositivos também se configuram em um instrumento para transmitir conteúdos específicos e desenvolver competências em diversos âmbitos (leitura, escrita e outras atividades de produção). (FANTINI, 2018, p. 76).

Os dispositivos digitais móveis devem ser considerados quando falamos em TDIC aplicadas à educação por serem ferramentas de acesso a internet. O uso desses aparelhos tem se ampliado nos últimos anos na população brasileira, como se pode ver nas pesquisas de caráter censitário feitas pelo CETIC (2020). Segundo esse centro de pesquisa, 98\% dos estudantes de escolas da zona urbana afirmaram ter feito uso dos celulares para ter acesso a internet em 2019. (CETIC, 2020, p.23). 


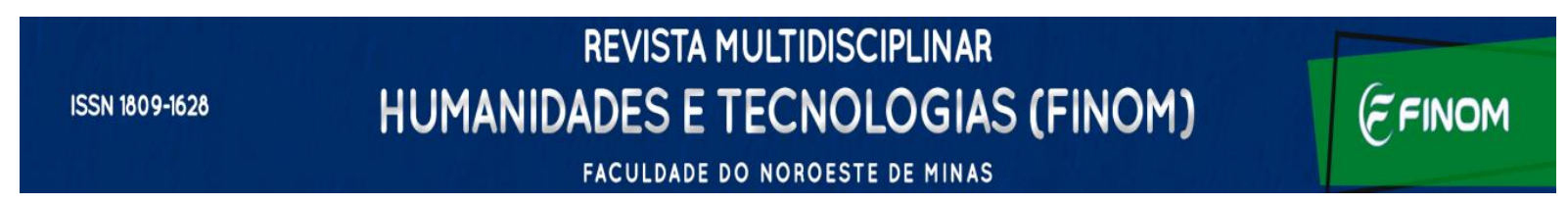

Junior; Menez e Wunsch (2018, p. 43), também concordam com o uso de dispositivos móveis ao apontarem:

[...] o destaque nas tecnologias móveis (celulares, smartphones, tablets dentre outros) se apresentam para ampliar e auxiliar no processo aprendizagem formal (instituições de ensino) ou informal (vida cotidiana), transpassando as barreiras de locais e horários específicos para aprender. [...] Assim, entendemos que com mediação e planejamento, o recurso pode tornar-se aliado em sala de aula adequando à realidade das novas gerações.

Nas observações da pesquisa de Kensky (2003, p. 9) as TDIC nos direciona para novas aprendizagens, e a sociedade no seu processo de construção criativa e inovadora impulsonará avanços no campo social relevantes e validados para o desenolvimento da humanidade.

Sobre o uso das tecnologias, nos estudos de Fantini (2018, p. 77), a autora enfatiza a importância dos profissionais da área da educação em geral terem conhecimento das mídias, bem como de seus dispositivos para terem argumentos ao lidar com as crianças em seus processos de aprendizagem para que elas possam ter criticidade e reflexão diante do que está posto.

Nesta direção, optamos pela metodologia da Revisão Sistemática da Literatura para compreendermos o que tem sido estudado acerca dessa temática na educação.

\section{Metodologia}

A pesquisa que será apresentada utilizou como metodologia a Revisão Sistemática da Literatura, que, segundo Faria (2016, p.94-102) “Trata-se pois de uma metodologia de pesquisa com rigor científico e de grande transparência, cujo objetivo visa minimizar o enviesamento do estado da arte, na medida em que é feita uma recolha exaustiva dos textos publicados sobre o tema em questão.”

Autores como Assis; Costa e Faleiro (2021) propoem a realização da Revisão Sistemática da Literatura em etapas, como pode ser visto a seguir o detalhamento das etapas utilizadas no presente trabalho:

1. Primeiramente foram estabelecidos os descritores de busca, na aba da pesquisa avançada do Google Acadêmico, com busca em qualquer lugar do artigo dentro do período temporal de 2011 a 2021, com a exclusão de palavras e/ou termos, sem patentes e citações; 


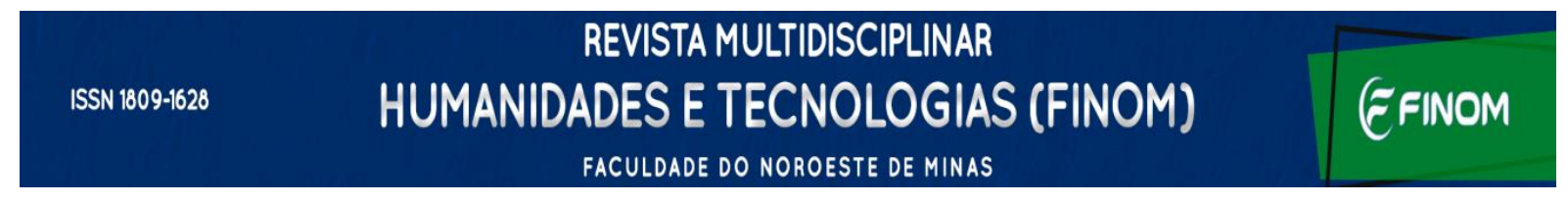

2. Após a primeira etapa, dentre os resultados disponíveis para consulta foram selecionados os artigos a priori pelos títulos;

3. A próxima etapa foi vericar se o trabalho era avaliado por pares e foram excluídos outros formatos que não fossem artigos completos, trabalhos como dissertações, teses, entre outros e trabalhos duplicados.

4. Consistiu da leitura dos resumos e palavras-chave;

5. Leitura dos artigos na íntegra;

6. Registro documental de informações que respondem aos objetivos da pesquisa e

7. Análise dos dados e discussão.

Utilizamos como descritores: TDIC e Alfabetização "tecnologias digitais", adotamos como critérios de exclusão na busca avançada: jovens, midiática, informacional, matemática, "na idade certa", “alfabetização digital”, "alfabetização em tecnologias digitais", "alfabetização midiática", "alfabetização na idade certa”, "alfabetização matemática", "alfabetização científica", "tecnologias assistivas", inclusão de autistas, cegos, surdos, transtornos advindos da Educação Especial.

Como critéros de inclusão, artigos disponíveis para download gratuito, publicações nacionais em língua portuguesa, bem como os demais critérios anteriormente informados na descrição das etapas.

A partir da coleta dos dados analisamos as TDIC utilizadas nas pesquisas, quais foram os desafios e potencialidades demonstrados nos estudos acadêmicos.

Figura 1: mostra a pesquisa avançada na base de dados do Google Acadêmico

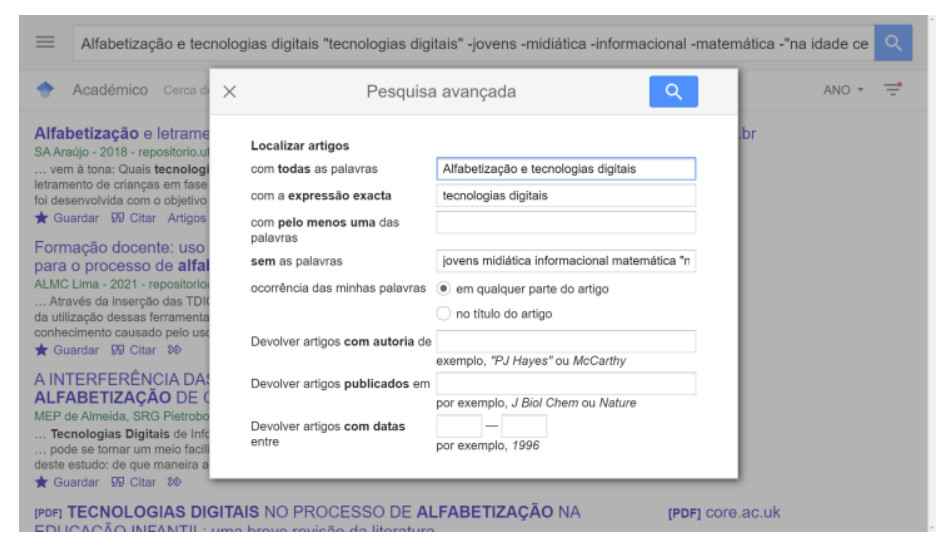

Fonte: As autoras, 2021.

A pesquisa foi realizada em dezembro de 2021, na qual foram selecionados oito artigos que versam sobre as TDIC na alfabetização. A priori foram selecionados 35 pelos titulos e posteriormente após análise de avaliação de pares, leitura dos resumos e palavras- 
chave reduziu para oito.

\section{Análsie dos dados e discussão}

Apresentamos alguns dados quantitativos que nos serviram de subsídios para análise qualitativa. De acordo com Minayo et. al (1994) a pesquisa qualitativa atende questões peculiares se preocupando com as demandas válidas que não podem ser quantificadas. São inúmeros os casos, procedimentos e eventos que não podem ser resumidos numericamente. A seguir gráfico ilustrativo do número de artigos publicados por ano.

Figura 2: Artigos por ano de publicação

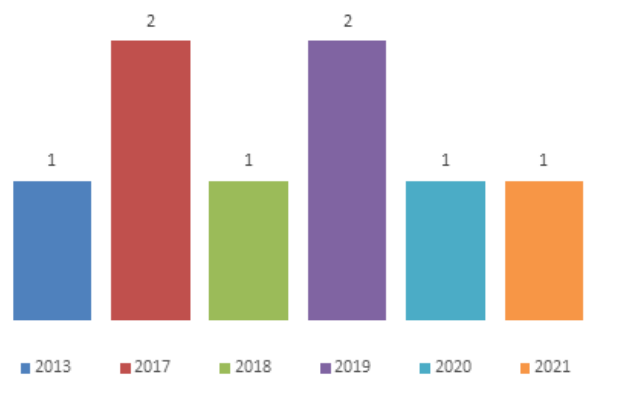

Fonte: As autoras, (2021).

Dentro do período considerado na pesquisa nos últimos vinte anos, obedecendo-se os critérios de inclusão e exclusão utilizados, foram selecionados oito trabalhos, sendo que para os anos 2013, 2018, 2020 e 2021 obteve-se um para cada ano, e dois para cada um dos anos de 2017 e 2019. Esses trabalhos foram, em sua maioria, aplicados em escolas públicas, como se pode perceber pelo gráfico a seguir.

Figura 3: Instituições de Ensino

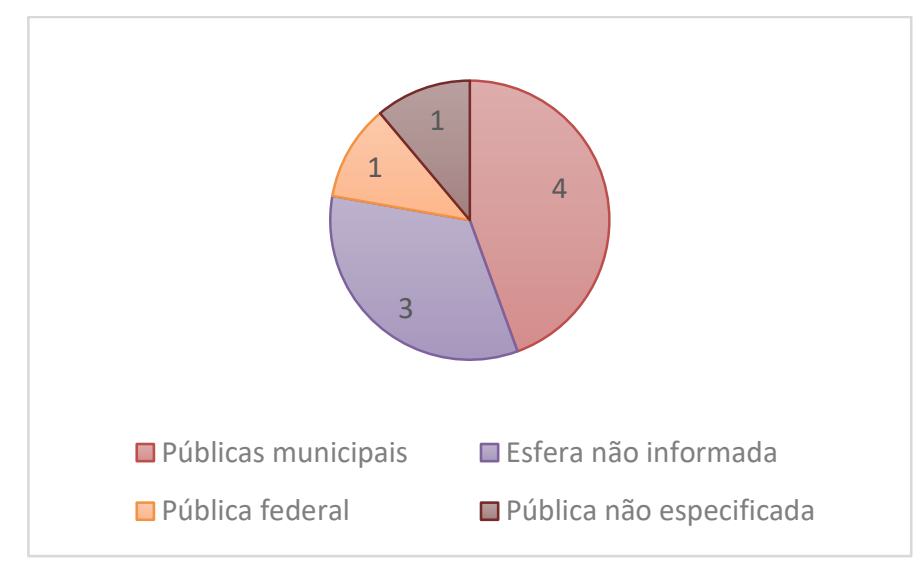

Fonte: As autoras, (2021). 


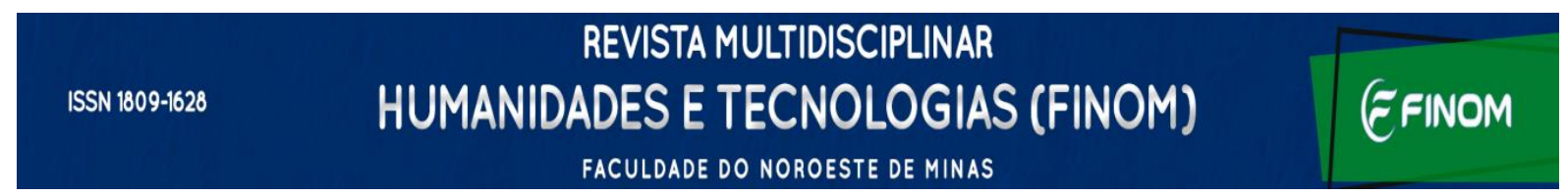

Como ilustrado no gráfico, das oito escolas que realizaram as pesquisas, quatro ocorream em escolas municipais, uma em escola federal, uma delas em uma escola pública que não informou a qual esfera pertencia e outras três que não apresentaram esse tipo de informação.

Sobre o nível de escolaridade e participação dos alunos nas pesquisas tem-se o seguinte:

Quadro 1: Escolaridade e Participação do alunado

\begin{tabular}{|l|l|}
\hline Escolaridade & Participação do alunado \\
\hline 30 ano do ensino fundamental & Sim \\
\hline $\begin{array}{l}\text { 20 ano do ensino fundamental com idade entre 7 e } 8 \\
\text { anos }\end{array}$ & Sim \\
\hline 10 ano do ensino fundamental & Sim (vinte crianças) \\
\hline $\begin{array}{l}\text { 10 ano do ensino fundamental, entre 6 e 7 anos de } \\
\text { idade }\end{array}$ & Sim \\
\hline $\begin{array}{l}\text { Educação infantil e o ensino fundamental - de 3 a } 6 \\
\text { anos de idade }\end{array}$ & Não \\
\hline $\begin{array}{l}\text { Ciclo de alfabetização infantil (10 ao 3o ano) do ensino } \\
\text { fundamental }\end{array}$ & Sim (oito crianças) \\
\hline Anos iniciais do ensino fundamental & Não \\
\hline 10 ano do ensino fundamental & Não \\
\hline
\end{tabular}

Fonte: As autoras, (2021).

Com a observação da tabela vimos que em alguns estudos o foco de atenção é o primeiro ano do ensino fundamental com cinco trabalhos com esse enfoque, enquanto que a participação empírica dos educandos também atingiu o mesmo número.

Dentre os trabalhos analisados interessa ressaltar as potencialidades das TDIC como ferramentas valiosas para a alfabetização de crianças. Os autores dos artigos pesquisados apontam como potencialidades das TDIC para a alfabetização:

- Motivação das crianças para participarem das atividades propostas;

- Facilidade de engajamento das crianças nas tarefas;

- As tecnologias despertam interesse nos alunos em executar as atividades e colaboração com os demais colegas para conclusão da tarefa;

- Potencialidade de autoria e formação cidadã;

- As ferramentas são atrativas, principalmente para os que têm facilidade no seu manuseio;

- Possibilidades didáticas de ensino-aprendizagem permitem a autonomia do aluno.

Essas potencialidades devem ser exploradas para intensificar o desenvolvimento infantil e aumentar as chances de sucesso de práticas pedagógicas voltadas para o contexto 
social da criança de modo que as suas aprendizagens sejam significativas.

Assim, temos um breve resumo de cada um dos oito trabalhos analisados.

Almeida e Pietrobon (2021), aplicaram um questionário online com sete docentes dos primeiros anos do ensino fundamental, para verificar sobre os possíveis usos da TDIC na sala de aula. Esses autores constataram pela resposta de cinco professores, que a escola onde atuavam não possuía laboratório de informática e dois disseram que utilizavam o laboratório a cada 15 dias. Professores da pesquisa avaliam as TDIC como relevantes no processo de alfabetização, porém alertam sobre a importância do equilíbrio e reflexão e também da necessidade da interação concreta do professor na sala de aula.

Na perspectiva de seis professores as TDIC facilitam a aprendizagem e o relato de um dos professores quanto a utilização do Google Meet, You Tube e WhatsApp como suporte tecnológico nas aulas remotas.

Os autores concluem o estudo acerca das TDIC na alfabetização como fundamental além de despertar o interesse dos/as estudantes. Abordaram a importância de políticas públicas para subsidiar a formação docente e estrutura física da escola.

Lima (2019, p. 152) traz como foco de análise os "pueri digitales, ou seja, as crianças que se encontram entre três e seis anos, em idade escolar de Educação Infantil e início do Ensino Fundamental", em processos de alfabetização.

O estudo desse autor traz o enfoque da aprendizagem da leitura e escrita associada aos aparatos digitais e midiáticos disponíveis. Ressalta a necessidade dos docentes considerarem as experiências dos alunos para que a aprendizagem seja significativa, uma vez que esses estão cercados no dia a dia por recursos digitais. Destacam a necessidade de serem utilizadas feramentas tecnológicas de maneira reflexiva para que o mau uso não interefira negativamente nos resultados a que se propõem.

Oliveira et. al. (2019) estudaram como unir as tecnologias digitais aos processos de aprendizagem da alfabetização. Tendo as tecnologias digitais inseridas nas metodologias de ensino capazes de contribuir significativamente na aprendizagem dos sujeitos.

Esse estudo propõe a utilização do software "Silabando" como ferramenta didática para intervenção na alfabetização aplicado pela pesquisadora, professora atuante na área. $\mathrm{O}$ jogo pode ser acessado gratuitamente pelo computador ou tablet e ser manuseado sem o uso de internet. A experiência contou com a participação de três professoras do ciclo de alfabetização para tecerem suas observações acerca do desenvolvimento dos alunos dos quais 
participaram da pesquisa.

O estudo durou quatro semanas, com a participação de oito crianças do ensino fundamental, compreendendo duas do primeiro ano, duas do segundo ano e quatro do terceiro ano com idade entre seis e dez anos de idade.

Os resultados indicaram avanços na concentração e na área cognitiva, os recursos audivisuais contribuiram no processo de leitura e escrita, o que leva a considerar os aspectos pedagógicos implementados eficazes e o jogo como possível recurso didático para o ensino.

Branco et. al (2018) propõem que para atender aos novos educandos nascidos na era digital é preciso ressignificar as práticas pedagógicas e se conectar com os/as estudantes. Dessa forma abordam os diferentes dispositivos móveis como aliados do conhecimento.

Esses autores fizeram um estudo com alunos do primeiro ano do ensino fundamental que se pautou na construção de uma história imagética que se desdobrou para diversas aprendizagens de leitura e escrita, assim como outros saberes interligados, proporcionou as crianças fazerem pesquisa no laboratório de informática e a descoberta de novos conhecimentos.

Depois da criação da história, tendo a professora como escriba, foi complementada com uma versão digital, os desenhos em folhas simples ganharam uma nova roupagem, de cartas do tipo baralho e receberam "QRCode (sistema de integração gráfica entre publicações off-line e links de internet)" (BRANCO et. al, 2018, p.8) que foram enviadas para uma plataforma e permitia a participação da família na criação de histórias com as crianças pro meio de tabletes, computador ou celuar.

Souza e Oliveira (2020) analisaram as potencialidades dos jogos digitais para aquisição da leitura e escrita de crianças nos anos iniciais do ensino fundamental por meio de uma revisão da literatura.

O estudo dessas autoras traz na pesquisa os pontos favoráveis como potencialidade de estimular a tomada de decisões, definição de pontuação, conflitos comum na vida cotidiana experenciados nos jogos, evidenciam que o bom uso dos jogos digitais podem estimular a criatividade, autonomia, pensamento reflexivo, ações cooperativas, além de motivar aprender, enquanto que o mau uso das tecnologias podem trazer pontos desfavoráveis como sobrepeso, comportamento estressante e antissocial.

As autoras analisaram três obras científicas sobre os jogos digitais relacionados a aquisição de leitura e escrita por crianças com dificuldades nessas aprendizagens e 
constataram que em todas as publicações há relatos de avanços na aprendizagem após a intervenção mediada pelos jogos digitais.

A utilização dos jogos conforme o estudo, estimulam as crianças na realização das tarefas propostas. Desde que incluídos da prática pedagógica com uma finalidade específica e mediada pelo docente. Nesse sentido alertam para a formação docente para intervir na utilização das tecnologias digitais.

Boas e Vallin (2013) buscam evidenciar o uso do computador como ferramenta tecnológica facilitadora no processo de aprendizagem de leitura e escrita de alunos do terceiro ano do ensino fundamental de uma escola pública municipal que apresentavam lacunas nos processos de alfabetização.

O trabalho desenvolvido fez uso do software Alfabetização fônica computadorizada e como resultado as crianças que não estavam no nível alfabético alcançaram essa fase e obtiveram ganhos significativos na aprendizagem. O estudo mostra que mesmo tendo que executar atividades próprias das fases iniciais da alfabetização no computador era motivador para os alunos, diferentemente quando aplicados sem o uso das tecnologias digitais em que as crianças ficavam desmotivadas e constrangidas por ter sido uma fase na qual já haviam passado. Mesmo os alunos frequentando aulas de reforço no primeiro semestre com atividades diferenciadas não ocorreu evolução considerável segundo observações da pesquisa, o que só foi visível constatar após inserção do computador na prática pedagógica.

Almeida, Fuck e Silva (2017) propõem analisar o uso de um software livre de edição de texto, como possibilidade tecnológica na alfabetização. A atividade foi realizada com uma turma do segundo ano do ensino fundamental, com faixa etária de sete a oito anos de idade, com a utilização do laboratório de informática.

Ressaltam a importância da formação docente para o uso das tecnologias digitais no cotidiano da prática educacional, em colaboração com o aprendizado pautado nas exigências da atualidade imersa nos meios tecnológicos e digitais.

Utilizam da gamificação com foco no sujeito que aprende, no seu processo de desenvolvimento e não pela recompensa propiciada pelo ato de jogar. Com isso, trazem outros elementos como o desenvolvimento de competências, autonomia, capacidade de resolver problemas, pensamento crítico como orientação para a prática pedagógica que tenha o intuito de desenvolver atividades gamificadas, assim como o conhecimento docente acerca da gamificação e o que se pretende implementar em sua prática pedagógica. 


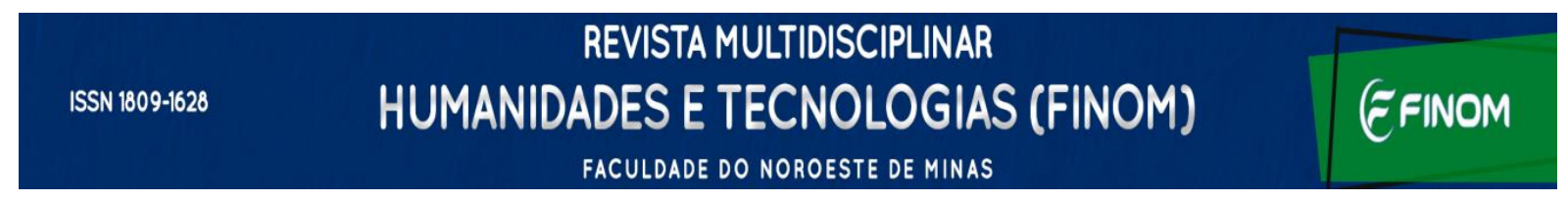

Como resultado observou-se o engajamento das crianças, interesse em executar as atividades e colaboração com os demais colegas para conclusão da tarefa.

Ferreira, Rehfeldt e Silva (2017) realizaram um estudo de forma colaborativa com uma professora do primeiro ano do ensino fundamental em uma escola pública municipal do Maranhão, com a utilização do vídeo como potencializador de aprendizagens de autoria, cidadania, leitura e escrita.

No estudo as crianças assistiram, como também produziram um vídeo e editaram, bem como realizaram pesquisas na internet no laboratório de informática com objetivos e práticas pedagógicas com aprendizagens direcionadas.

Os autores apontaram limitações como falta de estrutura física pelo restrito número de computadores disponíveis e falta de fones de ouvido.

As pesquisas analisadas apresentam possibilidades de uso das TDIC na alfabetização que podem agregar valor à prática pedagógica de professores e subsidiar de forma signficativa as aprendizagens na alfabetização.

Entretanto, algumas fragilidades também podem ser apontadas, como, por exemplo: alguns trabalhos não expoem com clareza o problema de pesquisa, outros não reportam o detalhamento da metodologia de pesquisa e em outros, ainda, pode-se observar fragilidades no relato dos resultados alcançados. Todavia, permanece o valor das pesquisas realizadas, que denotam a aproximação do papel do educador com o de pesquisador, essencial para a inovação na educação subsidiada pela mediação pedagógica com o suporte das TDIC.

\section{Considerações finais}

Percebemos com essa análise que as TDIC têm potencialidades para a inovação educativa quando associadas à prática pedagógica de forma intencional e direcionada na obtenção de resultados concretos de aprendizagens significativas. Observamos em todos os artigos analisados as contribuições das tecnologias evidenciadas, com relato de potencialidades de seus usos na alfabetização.

Encontramos também nos estudos desafios evidenciados nas pesquisas que demandam por políticas públicas quanto a formação docente para o uso das TDIC, bem como problemas relacionados a infraestrutura precária.

Concluimos nossa pesquisa com a reflexão de que as TDIC quando associadas de 


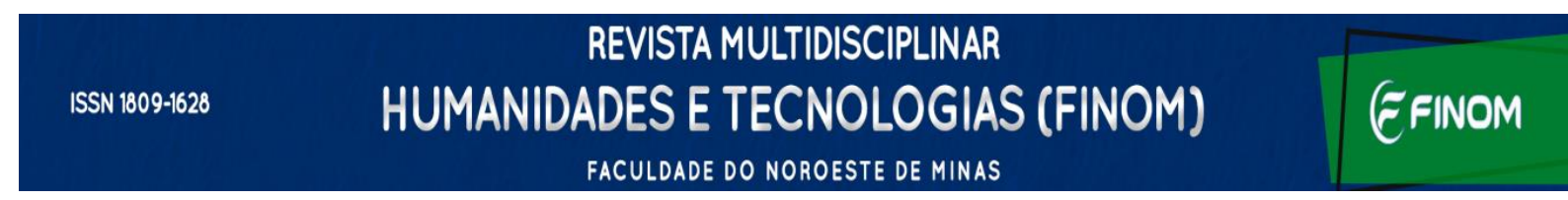

forma reflexiva ao contexto educacional produz avanços nas aprendizagens das crianças, pois estas se mostram receptivas, engajadas e motivadas a aprender. Aparentemente, as crianças se envolvem de forma lúdica em aparatos digitais que permeiam seus contextos fora da escola e por isso o aprendizado se torna significativo.

Acreditamos que ao darmos continuidade à pesquisa, iremos dialogar e refletir com mais pesquisadores sobre esse objeto de análise e percerber como as pesquisas têm evidenciado seus estudos na área das tecnologias digitais associadas à alfabetização. Sendo assim, este campo de pesquisa também terá potencial para contribuir para a formação e a prática docente.

\section{Referências}

ALMEIDA, Leonardo Rocha de; FUCK, Rafael Schilling; SILVA, Patrícia Grasel da. Estratégias de gamificação no processo de alfabetização: experiência em uma escola da rede pública. Redin-Revista Educacional Interdisciplinar, v. 6, n. 1, 2017.

ALMEIDA, Maria Eduarda Padilha de; PIETROBON, Sandra Regina Gardacho. A Interferência das Tecnologias Digitais no Processo de Alfabetização de Crianças do $1^{\circ}$ Ano. Revista A educação em verso e reverso: Dos aportes normativos aos aspectos operacionais, p. 60-75.

ASSIS, Maria Paulina de; COSTA, Elis Regina da; FALEIRO, Wender. Docência Universitária e Letramento Digital: desafios da formação de professores. Revista Diálogo Educ., Curitiba, v. 21, n. 68, p. 127-154, jan./mar. 2021.

Biblioteca Digital de Teses e Dissertações (BDTD). Página instutucional. Disponível em: https://bdtd.ibict.br/vufind/Search/Results?join=AND\&bool0\%5B $\% 5 \mathrm{D}=\mathrm{AND} \&$ lookfor0\%5B $\% 5 \mathrm{D}=$ Tecnologias+digitais+na+alfabetiza\%C3\%A7\%C3\%A3o\&type $\% 5 \mathrm{~B} \% 5 \mathrm{D}=\mathrm{AllFields} \&$ daterange $\% 5 \mathrm{~B} \% 5 \mathrm{D}=$ publishDate $\&$ publishDatefrom $=2011 \&$ publishDateto $=2020$. Acesso em: 13 set. 2021.

BOAS, Valéria Alvarenga Pimenta Vilas; VALLIN, Celso. Alfabetização de crianças utilizando recursos tecnológicos. Revista Eletrônica de Educação, v. 7, n. 2, p. 63-74, 2013.

BRANCO, Cristina Ferreira et. al. Ressignificando uma prática pedagógica de alfabetização: um novo olhar sob a égide das novas Tecnologias Digitais. Revista Carioca De Ciência, Tecnologia e Educação, v. 3, n.1, 2018.

BRASIL. Ministério da Educação. Base Nacional Comum Curricular. Disponível em: http://basenacionalcomum.mec.gov.br/images/BNCC_EI_EF_110518_versaofinal_site.pdf. Acesso em: 04 dez. 2021. 
FANTIN, Mônica. Crianças, Dispositivos Móveis e Aprendizagens Formais e informais. (C) ETD- Educação Temática Digital, v.20, n.1, p. 66-80, 2018.

FARIA, Paulo M.Revisão Sistemática da Literatura: Contributo para um novo paradigma investigativo. Santo Tirso-Portugal: WHITEBOOKS, 2016.

FERREIRA, Marinalva da Silva; REHFELDT, Márcia Jussara Hepp; SILVA, Jacqueline da Silva. Possibilidades para o uso pedagógico do vídeo no ciclo de alfabetização. Revista Tecnologias na Educação, v. 23, 2017.

FERREIRO, Emilia; TEBEROSKY, Ana. Psicogênese da Língua Escrita. Porto Alegre: Artmed, 1999.

JUNIOR, João Batista Bottentuit; MENEZ, Messiane Rose Correa Sá; WUNSCH, Luana Priscila. Aplicativos Móveis Para A Alfabetização E Letramento No Contexto Do Ensino Fundamental. Revista Tempos e Espaços em Educação, v.11, n.1, p.37-56, 2018.

KENSKI, Vani Moreira. Aprendizagem Mediada pela Tecnologia. Revista Diálogo Educacional, Curitiba, v. 4, n.10, p. 47-56, 2003.

LIMA, Francisco Renato. Tecnologias digitais da informação e comunicação na alfabetização e letramento dos pueri digitales: Práticas Leitoras na Tenra Idade. Revista Informação em Cultura, v. 1, n. 2, p. 132-155, 2019.

MARTIN-BARBERO, Jesús. A comunicação na educação. Tradução de Maria Immacolatra Vassallo de Lopes e Dafne Melo. São Paulo: Contexto, 2014.

MINAYO, Maria Célia de Souza (Org.). Pesquisa Social: teoria, método e criatividade. 21 Ed. Petrópolis/RJ: Vozes, 1994.

OLIVEIRA, Diana Nara da Silva et al. Perspectivas docentes sobre o uso das TDIC na Educação Básica em tempos de pandemia do COVID-19. Research, Society and Development, v. 9, n.12, p. 1-24, 2020.

ROJO, Roxane(Org). Alfabetização e letramentos múltiplos: como alfabetizar letrando? In: RANGEL, Egon de Oliveira (Org). Língua Portuguesa: ensino fundamental. Brasília: Ministério da Educação, Secretaria de Educação Básica, 2010. p. 15-36.

SANTOS, Adriano Miranda dos et al. As Tecnologias Digitais da Educação Como Metodologia de Ensino-Aprendizagem na Alfabetização Infantil: O Uso do Aplicativo "Silabando", Como Recurso Didático. Revista Educação: Políticas, Estrutura e Organização 4, p. 49-63.

SILVA, Francileide Targino da. As Tecnologias Como Aliadas da Alfabetização no Ensino Fundamental. Revista Artigos.Com, v. 14, p. 1-11, 2020.

SOUZA, Naiara do Prado; OLIVEIRA, Kleonara Santos. Jogos Digitais Como Objeto de Aprendizagem no Processo de Alfabetização: Considerações Sobre a Aprendizagem da Leitura e da Escrita. Diálogos e Perspectivas Interventivas, v. 1, n. e9790, p. 1-14, 2020. 